\title{
A PLACE-BASED PERSPECTIVE ON MARINE AND COASTAL SPACE
}

\author{
Kira Gee ${ }^{1}$, Daniela Siedschlag ${ }^{2}$ iD \\ ${ }^{1}$ Helmholtz Zentrum Geesthacht \\ Max-Planck-Str. 1, 21502 Geesthacht: Germany \\ kira.gee@hzg.de \\ ${ }^{2}$ Helmholtz-Zentrum für Umweltforschung \\ Permoserstr. 15, 04318 Leipzig: Germany \\ daniela.siedschlag@ufz.de
}

\begin{abstract}
Over recent years the sea has experienced re-interpretation as marine space, or more specifically as marine spatial planning (MSP) space. This article uses the concept of place as a contrasting interpretation to space, referring to place-making as a metaphor for the various ways in which meaning is created in the sea. As expressions of an intimate connection between experienced materiality and symbolism, places (unlike space) are never abstract, but always carry emotional dimensions. Place attachment can be the result of everyday profe

ssional links, recreational activities, or living by the sea, and arises despite the greater intangibility of locations in the sea. As a result of their greater physical intangibility, places in the sea may require more frequent (re-)making than places on land, pointing to the inherent importance (and value in their own right) of the associated (socio-cultural) processes of place-making. The ability to engage in place-making is thus an important avenue for expressing place-based values, an understanding which could be used to enrich marine spatial planning processes. Focusing more on the intimate connections people have with places in the sea and how quality of place matters to them could turn MSP into an enabler of place-making, becoming more of a rich and continuous dialogue around the multiple ways in which people interact with and value the sea.
\end{abstract}

Keywords: emotional attachment, meaning, place, place-making, quality of place, space.

\section{The rise of marine spatial planning space}

With the advent of maritime/marine spatial planning (MSP), concepts surrounding marine space have received renewed and much deserved attention. In northern Europe, MSP arose in the early 2000s from the very practical need of accommodating offshore wind farming as an emerging use, driven by national and EU policy and freshly agreed targets for renewable energy (e.g. Morf, Cedergren, Gee, Kull \& Eliasen, 2019). Planners in Germany and elsewhere found this a difficult challenge as, contrary to the common image of a wide and open space, the seas are busy places that already accommodated a wide range of uses and activities. The advent of offshore wind farming led to increasing competition for a resource - marine space - that had largely been considered abundant up to that point. Offshore wind farms also represented an unusual marine use. They occupy large areas, are highly visible and likely to be in place for many years - unlike most other less visible or transient uses such as fishing or oil platforms, which nevertheless may also have 
specific locational requirements, e.g. as a result of marine resource distribution.

To some degree, offshore wind farming can be credited with causing a shift in perception of marine space. Long neglected by many, the sea was suddenly perceived in a new light and by a new community of policy-makers and users. On the one hand, the marine environment was increasingly perceived as subject to multiple pressures, giving way to concepts such as the ecosystem approach to marine management (e.g. Farmer et al., 2012). On the other hand, technological progress, policy incentives and the increasing affordability of accessing more remote sea areas allowed new forms of interaction between humans and the sea to emerge. Infrastructure such as wind turbines or cables is the visible manifestation of these new relationships, epitomising types of use that do not make extractive use of the sea's resources but merely occupy large tracts of its space. As a result, instrumental value came to be assigned to marine space, enabling it to become an increasingly valuable resource in its own right.

At the same time, marine space also became reconfigured as planning space (Jay, 2010). This went hand in hand with questions related to boundaries, the socio-economic values MSP should give priority to, and the governability of marine space, both as a three-dimensional, fluid entity so clearly different from the land and an overlay of multiple territories and varying administrative responsibilities. The current practice of MSP mostly uses pre-existing administrative boundaries as planning spaces, although these are increasingly complemented by other, more informal planning spaces that transcend national and sub-national borders ${ }^{1}$. More importantly perhaps, marine planning space came to be interpreted in a similar way in many countries in terms of the instruments that are being applied, such as demarcating areas or zones and assigning priorities to uses. As a result, MSP creates a patchwork of spaces that may embody differing perceptions and values associated with the sea but which are nevertheless enfolded in the particular MSP way of conversing about and relating to the sea. The fact that a third of the world's exclusive economic zones are likely to have government-approved marine spatial plans by 2030 (Ehler, Zaucha \& Gee, 2019) indicates that the spatial language of MSP is likely to become an even stronger cultural and political force in future.

This article questions the current interpretation of marine planning space as an all-encompassing language for expressing human relations with the sea. It departs from the notion of relational space, i.e. the view that marine space as "made" by current versions of MSP is just one particular social construct - albeit a powerful one. Drawing on the concept of place, it asks whether alternative views might lead to different conceptualisation of marine space, and whether such alternative conceptualisations may also the way in which MSP is conceived and practiced.

To illustrate how different conceptions of the sea could lead to alternative spatial thinking, consider uses that require considerable investment in hard infrastructure (such as offshore wind farming). These uses usually require significant financial investment, which is why they go hand in hand with a desire for clear rules and regulations in order to obtain investment security. Rights are important to these uses, and a conception of marine planning space based on "hard" evidence (e.g. a scientific assessment of which space is particularly suitable for offshore wind) and delineates distinct and possibly exclusive areas is an advantage. In contrast, immaterial values that are expressions of more emotional relationships with the sea and linked to very different benefits derived from the sea are less about space but more about place. Place-based values tend to be difficult to map onto the standard MSP perspective as they are less spatially distinct and less clear-cut with respect to the (multiple) values they represent. This is not to say that different con-

\footnotetext{
${ }^{1}$ Examples exist in the Baltic Sea, North Sea and European Atlantic where a number of transnational projects have been carried out on MSP.
} 
cepts of space and place cannot coexist, or even be fruitful for MSP in terms of expanding the understanding of planning space. It simply points to the fact that space and place are expressions of different ways of knowing the sea, and that each may lead to different conclusions with respect to the sea as a planning space.

In the following we briefly summarise the rational-scientific paradigm that has been a fundamental prerequisite for the current spatial paradigm of MSP, as well as more recent thought on "soft space" (e.g. Allmendinger, Haughton, Knieling \& Othengrafen, 2015; Jay, 2018). We then use the lens of "place" to illustrate a different way of relating to the sea, focusing in particular on the emotional dimension of place. We end with a summary and a brief discussion of potential implications for MSP.

\section{The sea as a planning space}

Given the increasing value of space as a resource, the desire to resolve conflicts of use and enable efficient use of the sea have been the central drivers for MSP. This is the case in northern Europe but also in other countries that are developing marine spatial plans (Ehler et al., 2019). MSP is commonly defined as the "public process of analyzing and allocating the spatial and temporal distribution of human activities in marine areas to achieve ecological, economic, and social objectives" (Ehler \& Douvere, 2009, p.18). The central part of "analyzing and allocating human activities in marine areas" usually translates into variations of zoning concepts, where one use, or a combination of uses, is given priority over others in distinct marine areas.

In this particular reading, MSP is closely related to a "rational" perspective of marine space (Davoudi \& Strange, 2009; Jay, 2010), a construct that has become a firm standard in MSP practice. It is close to the view of space as a location where objects and things exist objectively and whose dimensions can be discovered by analysis (Healey, 2010). Although there is recognition that marine space is three-dimensional and that certain, mostly ecological functions cannot be contained, the view is nevertheless of a space that is amenable to division and delineation. This "rational" perspective of space is enabled by various other elements: the ability to produce increasingly sophisticated maps of marine space, the existence of United Nations Convention on the Law of the Sea and maritime boundaries such as territorial waters and exclusive economic zones (EEZ) (e.g. Pyć, 2019), and the belief that marine uses can and should be consciously ordered in an integrated, strategic way so that socio-economic and ecological objectives can be achieved (Ehler \& Douvere, 2009). As such, the rational construct of marine space - and the notion of governing this space is also related to the concept of territory as an area under the jurisdiction of a state, or (in the case of the EEZ) an area associated with certain sovereign rights and duties.

\section{Towards other notions of marine planning space}

Recent research has given rise to a more critical perspective of MSP. Some of this criticism has focused on the instrument of MSP and its current application (e.g. Flannery, Healy \& Luna, 2018; Janßen, Varjopuro, Luttmann, Morf \& Nieminen, 2018), but questions are also being raised from the perspective of geography (related to the spatial nature of the sea, e.g. Steinberg, 2015) and planning (related to the nature of planning space, e.g. Jay, 2010). While the questions that are being asked in the two disciplines differ, it seems obvious that the understanding of ge- 
ographical space cannot be dissociated from planning space as shifts in one can potentially give rise to shifts in the other. This can be observed in the emergence of more fluid concepts of marine space and the tensions these are causing with fixed notions of territory (Haughton \& Allmendinger, 2015). The concept of "soft space" (Allmendinger et al., 2015) is a relatively recent perspective applied to the sea, derived from the observation that spaces are being created for particular purposes that are not constrained by geographical and organisational boundaries (Jay, 2018). Among the central characteristics of soft spaces are their less clearly-defined, 'fuzzy' boundaries and their bringing together of new configurations of actors and forms of collaboration (Jay, 2018). As such, soft spaces are related to the notion of spatial imaginaries ${ }^{2}$ and identity and have been shown to be used in a strategic way for identity-making (Haughton \& Allmendinger, 2015).

These perspectives have emphasised the relational view of space, which is the notion that there is no absolute "fixity" of maritime space. Space is a social construct, and as such is arbitrary and fluid. Configurations of marine space are always shifting in response to changing actor constellations, networks and interests, making them "forever in a state of becoming" (Haughton \& Allmendinger, 2015). It also means that overlapping constructs of marine space exist concurrently, each with its own constituting relationships (Ehler et al., 2019). Examples are ecosystem-based management, land-sea interactions (a notion derived from the EU Marine Spatial Planning Directive) (EC, 2014), or nested forms of governance across multiple scales, all of which are concepts that originate with a particular way of thinking about the sea, its spatiality and territoriality, and not least also how it can and should be governed.

\section{The sea from a place-based perspective}

\section{Definitions of place}

Jay $(2018, p .453)$ notes that the understanding of the spatial in MSP usually refers to a "physically-deterministic understanding, expressing the aim of simply allocating space to functional uses". In line with his view that the term "spatial" has yet to embody a fuller range of ideas in the marine context, we propose the concept of place as a way of achieving this. In this contribution "place" draws on the tradition of humanistic geography and landscape research (Relph, 1976; Tuan, 1977), which offers ready links to the idea of soft space, especially through aspects such as identity-making and cultural and emotional connections to the sea. We emphasise that place and place-making are also widely discussed in spatial planning, where improved place-making and better quality of places have been described as desirable outcomes of spatial planning processes (Healey, 1998). Place also features in the conception of spatial plans, which can be seen as an organising framework for managing spatial change and "weaving together the social, economic, environmental and physical dimensions of what makes up a place" (Healey, 1998, p.1). In this article, we explore the nature of place in more detail, focusing on the idea of deeper meanings, symbolisms and internal images associated with space.

Space and place are both relational concepts, in that they are created by diverse social, economic, cultural and physical processes and therefore subject to change. In geography, an important take on space is that it represents an entity without social connections and therefore an abstract and emotionally distant concept (Tuan, 1977). Space becomes place when it is imbued with mean-

\footnotetext{
${ }^{2}$ The concept of an imaginary, according to Jessop (2012, p.17), "denotes a simplified, necessarily selective "mental map" of a supercomplex reality".
} 
ing (Relph, 1976; Tuan, 1977), which can occur either through direct sensory experience or be mediated by cultural symbols. Based on the understanding of places as "made" place has also been described as the attempt to create "permanences" from the flow of processes that are creating spaces (Harvey, 1996, p.53, quoted in Davoudi \& Strange, 2009). Places are therefore expressions of an intimate connection between experienced materiality and symbolism, emphasised by Saar and Palang (2009) who describe places as midway between objective fact and subjective feeling. Tuan (1977) points to the active element of shaping places in his description of them as "centres of meaning constructed out of lived experience". Ingold (2000, p.192) similarly notes the importance of "people's engagement with the world, the business of dwelling" as a key to the uniqueness of places. An important aspect is that over time, places take on their own significance in the lives of people (Tuan, 1977), not least as a source of individual and collective identity (Healey, 2010) and home (Siedschlag, 2018). Ingold (2019) refers to the "holding capacity" of places in this context, i.e. their capacity to provide safety and security both literally (in the sense of firm ground) and figuratively (p.351). Emphasising the multi-dimensionality of place and the fact that it more than a locality, Jessop, Brenner and Jones (2008) argue that place should be viewed as a specific location, as a wider territory, as consisting of networks and as extending across different scales.

The central dimension of place as opposed to space is therefore its association with subjective experience and meaning. Unlike space, place can be a safe haven, a place of belonging, a source of identity and home, and can thus be meaningful in ways that space cannot. Places are loved by people "for a thousand reasons that cannot be enumerated, which we are not even aware of and which are nevertheless deep in our blood" (Tucholsky, 1929/2011, quoted in Siedschlag, 2018, p.123), representing a palimpsest of past and present interpretations and imaginaries. While space can be associated with material value - and could be apportioned in MSP based on economic rationales, for example (Zaucha, 2019), place is more intimately associated with immaterial values that may be difficult to articulate and even harder to confine within definitive boundaries (Gee et al., 2017). A place experience goes beyond the use value of the place (Eisenhauer, Krannich \& Blahna, 2000), and the experience of losing treasured places can be profound (Siedschlag, 2018). Places therefore always have an emotional dimension, which space as an abstract concept does not; minus the strategic and intentional dimension which is lacking in the concept of place, they could be characterised as collective spaces of identity whose boundaries are indistinct and variable in line with personal perceptions, feelings of belonging and scope for action.

\section{Place-making, sense of place, place attachment and identity}

If place arises from assigning meaning to space, an obvious question is how this occurs. Place-making has collective and individual dimensions, linked on the one hand to the idea of places representing social values and spheres of possibility (Kaschuba, 1985), emphasising places as cultural constructs and place-making as a cultural activity. Moreover, "making" requires action and communication, and there are power relations and interests that drive the production of places (Wardenga, 2002). On the other hand, place-making is very much a personal experience, which is related to perception and different ways of knowing and also mediated by culture. The concept of "encountering" the environment is a useful consideration here (Hull \& Stewart, 1995), which is the idea that it is not merely the objects or people within a particular setting that matter but more so the feelings, thoughts and other subjective qualities arising in the person during that encounter. Place is therefore inherently linked to perceptions (sensory and otherwise) and individual emotions. This is not dissimilar to the different modes of environmental experience discussed by Ittelson, Franck and O'Hanlon (1976), including the environment as an external place, 
as emotional territory, as self, as a social system, and a setting for action.

The emotional and cultural dimension of place-making also runs through the related concepts of sense of place, place attachment and identity. Relph (1976, p.76) noted that "every identifiable place has unique content and patterns of relationship that are expressed and endure in the spirit of place". Sense of place thus represents a combination of what could be termed "intrinsic personality" of the environment and the "emotional attachment to localities developed by individuals and communities in the course of living and growing within the setting of home" (Tuan, 1975; Muir, 1999, p.273). It has been noted that the emotional bond between an individual and a particular place is mediated by (1) the perception of particular features of a specific setting, (2) the specific experiences associated with this perception (such as aesthetic experiences) and (3) the addition of personal and collective meanings to this experience (Cantrill \& Senecah, 2001). It is the latter which lead to an affective bond between the individual and the particular place (Cantrill \& Senecah, 2001). Place attachment can thus be understood as encapsulating the value people ascribe to this emotional bond, or the importance assigned to the place by individuals and groups in a specific cultural context, so that strong place attachment is almost always an expression of a strong emotional connection between people and a place. Adapting Hasse (1999) who discusses this for human-nature interactions, places can be said to carry an "emotional imprint" (Hasse 1999, p.61, translated by D. Siedschlag).

People's identities are partly created through defining themselves in relation to places (Jorgensen \& Stedman, 2001). On the one hand, this relates to identities in the sense of "being from somewhere", or the experience of places as home (Ratter \& Gee, 2012). On the other hand, there are experience-related identities, such as professional or recreational identities, derived from engaging with places in a different way. Professional or recreational identities may be linked to different emotional bonds with places, such as having a regular surfing spot, but it is important to bear in mind that place attachments and identities are never one-dimensional in that a regular angling spot (leading a person to identify as a successful angler, for example) could also be appreciated for its beauty or associated with a long family history of angling (Gee et al., 2017). What matters is that strong place-based identities may go hand in hand with strong place attachments, which may find expression in resistance to change and a defensive attitude to that place. Placebased identity is thus revealed to be closely related to places as spheres of action, turning back to the idea of place being generated through cultural activity and engagement.

Last not least, there is also the notion that scale matters, in that different geographical scales of place are linked to different experiences and therefore emotional distances (Saar \& Palang, 2009). Lowenthal (1978) makes the point that attachment to a specific place "is apt to reflect some intimate connection, like growing up in it", while attachment to a larger unit such as a landscape "is more apt to reflect scenic or recreational preferences" (p.378). Place, however, can be defined at several scales, so that a coastline, for example, could be considered both a landscape and a place. Ultimately, place is largely a subjective experience, which can occur with differing intensities (expressed as strong or less strong place attachment) and at different scales.

As our first interim conclusion, we therefore emphasise that the meanings assigned to objects (place-making) and the values subsequently assigned to places (place attachment) have strong emotional dimensions and are culturally contingent. In the next section we briefly expand on the role of culture before considering the question of what places can and do exist at sea. 


\section{The role of culture in shaping place}

Places have long been viewed as historically and culturally contingent, in that people and places emerge through their relations with each other (Cobb \& Ransley, 2019). Culture is an important determinant of how objects are perceived and encountered and therefore how places are made. The dictionary (Merriam Webster, 2019) defines culture as the "customary beliefs, social forms, and material traits of a racial, religious, or social group", or "the characteristic features of everyday existence (such as diversions or a way of life) shared by people in a place or time". Here we define it as the material and immaterial practices that shape the world as we see and experience $i^{3}$; these practices are in turn influenced by the world. Some cultures are distinctly more maritime than others, such as those of island nations (Ratter, 2018) or fishing and whaling communities. Tangible and immaterial practices, stories and traditions influence how societies generally relate to the sea, not least by shaping the degree to which the sea is rooted in national or local consciousness and sense of self. Today, most societies have multiple imaginaries of the sea that exist in parallel, each of which influences society's engagement with the sea. For example, viewing the sea as welcoming or intriguing place is likely to invite exploration or recreation, while a negative image of the sea might lead to a more defensive and disengaged attitude.

This relationship, however, and the imaginaries of the sea within a society are not static, and views are rarely singular. Factors that can change a society's or community relationships with the sea, and with these maritime cultures, could be technological, societal or political change. In North Frisia in Germany for example, an essentially maritime outlook that had developed and persisted for many centuries became terrestrial as a result of shifting power relations in the $19^{\text {th }}$ century, leading people to turn their back to the sea and only re-discovering it again much later in a different context of leisure, health tourism and recreation. The advent of offshore wind farming described in the introductory section is an example of technological change that altered society's relationship with the sea. Namibia is an essentially terrestrial nation that has only recently discovered the ocean as a place of opportunity through its recent focus on "blue growth" (Finke, Gee, Kreiner, Amunyela \& Braby, 2020). Viewed through this lens of the material and immaterial and the relationships between society and the sea, culture can be said to determine the types of places that can arise within a particular society at a particular location and at a particular point in time.

\section{Place and the sea}

Relationships between people and the ocean are manifold and contribute to shape sense of place, and personal identity (McKinley, Acott \& Stojanovic, 2019). Various lenses are being employed to explore these relationships, including the concept of cultural ecosystem services (e.g. Liquete et al., 2013), sense of place and well-being. The nature of human experience in or by the oceans is a central concern of studies, some of which specifically touch upon the relationship between affect, emotion and place in marine and coastal settings (McKinley et al., 2019).

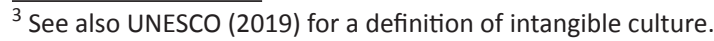




\section{Direct experience of the sea}

Fishing communities are a particular focus of studies surrounding identity and more direct experiences of marine space. They reveal how the engagement with the sea leads to collective community identity and also emotional attachment to places in the sea (expressed e.g. as a sense of freedom) (Urquhart \& Acott, 2013). A strong sense of belonging to the sea has also been found in study of Irish and Scottish Gaelic fishing communities, described as "not so much a landscape, not a sense of geography alone, nor of history alone, but a formal order of experience in which all these are merged" (MacKinnon \& Brennan, 2012, p.7). The authors emphasise that those working with the sea carry a deeper way of knowing the sea which is distinct from more formal ways of knowing. Both Howard (2019) and MacKinnon and Brennan (2012) find this reflected in the place names given to the sea by fishermen. This knowledge, they latter argue, also encompasses emotional energy as an indicator of belonging to the sea.

Still, it is difficult for non-marine cultures to imagine how place-making can occur at sea in the sense of being at home in them. After all, it is an environment "where nothing lasts" and "that offers no secure bed on which to found a shelter" (Ingold, 2019, p.351). The answer lies in the different ways in which place can be made in the sea, which in turn depend on different forms and intensities of engagement and ways of knowing the sea. As the sea can only be experienced indirectly by humans, different activities gives rise to very different "dwelling experiences" (Howard, 2019). While some activities such as cruising are temporal and rather indirect forms of engaging with the sea (representing a brief "going to sea from home", Ingold, 2019, p.351), others such as fishing or diving, or creating fishing grounds would lead to a much more immediate and more permanent way of experiencing the sea, more in the sense of "making a home at sea" (Ingold, 2019, p.351). Place-making at sea thus strongly resonates with geography's idea of an 'internal' perspective of places (Cosgrove, 1984), which focuses on the participants and 'makers' both as collective and entities, the process of 'making' as a socio-cultural process, and the intimate involvement with experiencing and shaping places as an individual experience.

The experience of the sea is also a special kind of experience for people who do not make a living from the sea but use it for recreation. This quote from an interview with a coastal resident in North Wales $(\mathrm{Gee}, 2015)^{4}$ emphasises the relationship between affect, emotion and place in the special sea experience when out on the water sailing:

When I'm way out at sea, it's peaceful. Large expanses of nothing. (...) You can find wilderness in country places, and that's wonderful. But this is different, you know, this continual motion, continual play of light.

Emphasis is made of the unique type of experience afforded by the sea, which is also an aesthetic experience. Another recreational sailor and diver describes the essence of the sea experience as the vastness of it, again as an emotional experience:

Just being on the sea, and in the sea, is an incredible experience. (...) You feel the vastness of it. You feel it in a boat, but so much more when you're in the water. Particularly if you're away from the land. And are part of it rather than just on it.

A third person links their experience of the sea to the experience of wildlife and tranquility: I'm on the water every day. The tranquil beauty of it. Freedom. And sea life. Bird life, puffins, just general sea birds, fishing, seals.

\footnotetext{
${ }^{4}$ A small pilot study was carried out by the author in 2014 on the North Wales coast to elicit people's sense of place with respect to the sea. It sought to determine the location of special sea places, their significance to people and any related place attachment, expressed through the values people associate with these places and the benefits they obtain from them. 100 household questionnaires were distributed (31 returns), and 7 interviews took place with local residents who identified as sea users.
} 


\section{Indirect experience of the sea}

But even people who rarely engage with the sea directly report a profound sense of belonging to the sea, simply by encountering the sea on a daily basis as part of everyday life on the coast. In the same small study in North Wales, when asked whether the sea was important to them and why, one resident stated:

Crucial. The sea is one of the few areas left as nature intended it. No construction, nobody trying to monetise it, nobody trying to monopolise it for private gain. Just nature with rarely humans in sight.

Another respondent said: It is in the sense that I feel it improves my quality of life to live near it and be able to see it, walk by it etc.

Many of these sentiments are echoed in another study of coastal places and their emotional dimensions carried out by Siedschlag (2018) on the German North Sea coast of Schleswig-Holstein, an area with long-standing sea-related traditions and lifestyles. The vastness of the sea and its endless horizon (echoed in the quote above) is a quality that repeatedly features in interviews, confirming Greverus' (2006, p.108) observation that coastal regions are ideal places for those "addicted to the horizon". More importantly, though, the sea emerges as a place of longing and home. Both for mainland and island residents the North Sea is of strong symbolic significance and "exerts a rather therapeutic and spiritual impact" (Döring \& Ratter, 2015, p.454). It confirms the findings of an earlier publication which described the particular quality of the North Sea as "its combination of physical reality and imagined place" and "the aesthetic seascape and the idea of untouched nature taking precedence over views of the sea as a utilitarian space" (Ratter \& Gee, 2012, p.132). The emotional layers of meaning associated with the sea are exemplified in a quote from an interview with a 52-year-old woman born on the German island of Pellworm (Siedschlag, 2018, translated by K. Gee):

(...) As a young person I only loved the sea. When we went on a school trip to the mountains: Oh, terrible, high mountains. It was all terrible, there had to be water. (...) It is difficult to imagine living on the mainland. Because I think I need the North Sea. (...) The North Sea is a, well, an element that strongly attracts me. Or water generally. Maybe it is this, this I believe, is my home.

Both in the case of North Wales and in northern Germany, the sea is experienced as an unquestioned dimension home and essential contributor to quality of life. As noted by other authors (Cobb \& Ransley, 2019; Wickham-Jones, 2019), the experience and making of place is seamless, transcending the land-sea boundary. There is emotional investment in the sea, as well as specific place-making when sailing or diving; there is also a place for the sea in the collective memory of the respective coastal communities.

\section{Implications of place attachment}

Emotionality is an important force in galvanising action (Kearns \& Collins, 2012; Ratter \& Gee, 2012). We care when something matters to us personally and deeply, usually as a result of personal, intimate connections to persons, places or experiences. The greater the emotional investment in a place, and the greater the meaning assigned to it, the greater the likelihood of strong attachment to the place and the greater the emotional consequences of a perceived threat or loss. 
Emotions that may come to the fore in such cases include discomfort, dissatisfaction, indignation, sadness, and feeling uprooted, an extreme version being the experience of physical pain (Siedschlag, 2018). A study in New Zealand revealed deep love for a particular coast, encompassing feelings of connection, sacredness and reverence, linked to feelings of anxiety in the face of coastal development (Kearns \& Collins, 2012). Feelings of anxiety were also found by Gee (2010) where the open horizon as a deeply treasured sea experience was imagined to be threatened by offshore wind farming. Threats to places can include physical change (which may be sudden or gradual), but also changes in how places can be experienced, e.g. as a result of a sudden influx of tourism or changes to the accessibility of a place.

Places are perceived differently by people, and their perception and importance shifts over time. Tensions often arise between the desire to preserve on the one hand (reflecting the desire to resist change and seek to maintain the status quo) and the desire to develop or improve (regarding change as an essential strategy of preservation or survival). This tension may even arise within the same person where internal conflicts between opposing values may lead to uncertainty as to the right course of action. In the New Zealand example, emotional connections with the coastal environment proved to be a resource and motivation for place-protective action (Kearns \& Collins, 2012). In the case of offshore wind farm development on the northern German coast, the utilitarian perspective of the sea and its perception as a place that can and should be used was tempered by a strong desire to protect, which was found to be driven by a conservation ethic based on a sense of what constitutes appropriate or the 'right' human action (Gee, 2010). Human relations with nature thus emerge as another important dimension particularly of sea places, as there is a strong sense of the sea as somehow different from the land and less implicated by human actions than other places ("the sea as one of the few areas left as nature intended it", as expressed in one of the quotes above). This feeling persists even in those who are exposed to the sea's more threatening nature (Siedschlag, 2018).

\section{Summary and conclusions}

This article set out to question the current abstract interpretation of sea space as a foundation for MSP. It used the concept of "place" as discussed in humanistic geography to highlight the sea as a meaningful place, as opposed to the more distant concept of space (e.g. Tuan, 1977). 'Place-making' in this context (and understood as distinct from the use of the term in planning, e.g. Healey, 1998) is used as a metaphor for the various ways in which meaning is created in the sea. This is revealed to be a culturally and socially mediated process, where meaning is assigned to objects and experiences based on individual perception, action and different ways of knowing. Places are linked to the material world in that they find expression in distinct locations, but also the immaterial world, in that they represent the "collection of meanings, beliefs, symbols, values and feelings that individuals or groups associate with a particular locality" (Williams \& Stewart, 1998, p.19). Quality of life, sense of place and also pride of place are key benefits derived from the engagement with places (McKinley et al., 2019; Siedschlag, 2018). The important message is that places in this understanding are never abstract or distant, but always carry emotional dimensions, not least derived from the creative process of actively engaging with and thereby shaping them. As symbols of socio-cultural practices and the meanings associated with these practices, a key dimension of places is therefore the possibility to engage in their making. 
We also suggest that the dialectic tension between the dynamic and static is more pronounced in the sea than on land. Given the natural mobility of the marine assemblage (Steinberg, 2014), the objects that can become carriers of meaning in the water column do not lend themselves to being moulded like a landscape would. At first glance, this makes sea places harder to associate with the notion of distinct localities or places as keepers of past traces of human engagement. Yet places in the sea do have material dimensions, and they do have stability, although this may not be in the classic sense of locational stability. Places may be reasonably stable within themselves as a particular assemblage, but they may be drifting, shifting entities, with variable boundaries that need to be 'felt' rather than seen. More so than places on land, which seem to hold evidence of (past) human activity for longer, places in the sea therefore require more active creation, or constant recreation, in order to ensure a semblance of permanence. An example are the specific localities where people engage in a particular activity, such as good surfing spots or named fishing grounds. All of these places may change their location or size in response to the ever-dynamic marine environment, yet they still persist precisely because people are continuously searching them out and re-tracing their boundaries. Other places in the sea have more obvious fixed physical manifestations, such as trawling grounds (Howard, 2019) which are the result of active husbandry by fishermen. It could be that the making of places, understood as the demarcation of localities by means of meaningful activity, is more intuitive and flexible in the sea, dependent on ongoing practices but also tradition encapsulating past knowledge and social action in the form of "ways of doing things". This permanence of place values despite the lack of a visible, precisely bounded location, and the value of places as arenas for action, could be an important lesson sea places can teach, not least in terms of dealing with these intangible values as part of planning processes.

The article also showed that the emotional connections with the sea are diverse. They can be the result of intimate and everyday professional links (such as commercial fishing), recreation, or living by the sea, and can be more or less place-specific. Another important lesson is that places and place-making in the sea generate strong emotional attachment despite the greater intangibility of locations, and despite the fact that such emotional connections are often not made explicit. The emotional attachment to places in the sea has been captured in recent work on the benefits people derive from the sea in various ways, both material and immaterial, as well as work on perceived threats to sea places, using emotionality as a currency for expressing value. There is also deep emotional attachment to the sea as a whole and as a place in its own right, expressed by people who use the sea for work or recreation but also people that gaze at it from the shore. This can be accompanied by a deep-seated sense that the sea should be protected, both as an existential value and for the sake of preserving the sea as a place that can deliver unique experiences.

So what are the lessons that could be drawn from this place-based perspective for the practice of MSP? Arguably, the place-based perspective is already a feature of MSP processes to some degree. Some attempts at incorporating socio-cultural values and attachments into MSP have been made that focus on locations and the spatial dimensions of people's connection with the sea, for example by delineating areas of high socio-cultural value from other locations of less perceived value (Gee et al., 2017). This recognises that some place-based values will have stronger locational links than others; in some cases, such links may be indirect or seasonal. This type of approach, however, will have limitations if place is not understood as an entity with a definitive location and definitive boundaries, as is the current requirement in the case of zoning-related plans. While some of these limitations could be overcome with the aid of different mapping techniques, such as drawing 'fuzzy' rather than absolute boundaries, it may not do justice to the nature of some sea places, as it would still attempt to confine the essentially mobile into a planning outcome 
that even with the best of intentions must still fix places in space, at least for a period of time. At the same time, given that cherished or important places are also related to a longing for their stability, places could also benefit from the temporary fixity of a marine zoning plan in terms of visibility - as long as the locational shifts of such places are not too sudden or too unpredictable for the life span of a marine plan.

In order to move towards a more refined concept of the sea as a planning space, two avenues seem worth exploring. The first is to give greater weight to the role of quality of place in the sea. Unlike quality in the sense of qualities - i.e. suitable spaces for particular activities - this means quality of place in terms of the role places play in the lives of people. This would require a closer look at the diversity of sea places, their roles, and why and how they matter to people. It would also require more research on how they might be linked to possibly differing, or multiple place-related identities. The second avenue, closely linked to the first, is to engage more with the emotional attachment people have to places, which is critical for identifying future visions of the sea. It is also critical for dealing with conflicts that might arise as a result of new developments and change, as highlighted by the cases of offshore wind farming and coastal development and the perceived threats these have posed to valued places. Both avenues require a view of MSP that is also about emotionally distant space, but which focuses more on the intimate connections people have with places in all their various forms. In this view of the sea as a planning space, MSP is an enabler of place-making, opening up spaces of possibility, recognising the manifold ways in which people relate to the sea, and including a wide range of people not only in planning decisions but also in the fundamental process of understanding human-marine relations. While the intention of a marine spatial plan is precisely to develop an element of fixity for sea uses, and to give greater planning security to those uses requiring specific spaces as a result, MSP as an enabler of place-making would become more of a continuous dialogue around multiple place-based options - planning the sea as a space of possibilities and remaining more open to the unforeseen (Jay, 2018). This means becoming attuned not only to the values ascribed to sea places, but also the processes that are essential for their creation - understanding places as culturally contingent and understanding the cultures that create them. An ongoing dialogue is therefore required with the multitude of users and creators of places in order to stay attuned to shifting practices and values, and appreciate which values have greater importance and permanence. This would also recognise that MSP is itself a fluid and culturally contingent concept that neds to be responsive to changing views of planning space.

\section{References}

Allmendinger, P., Haughton, G., Knieling, J., \& Othengrafen, F. (2015). Soft spaces, planning and the emerging practices of territorial governance. In P., Allmendinger, G., Haughton, J., Knieling, F., Othengrafen (Eds.). Soft Spaces in Europe: Re-negotiating governance, boundaries and borders (pp. 3-22). Routledge.

Cantrill, J., \& Senecah, S. (2001). Using the 'Sense of Self-in-Place' Construct in the Context of Environmental Policy-Making and Landscape Planning. Environmental Science and Policy, 4, 185-203. https://doi.org/10.1016/S1462-9011(01)00023-5

Cobb, H., \& Ransley, J. (2019). Moving beyond the "scape" to being in the (watery) world, wherever. In T.J., King \& G. Robinson (Eds.). At home on the waves. Human habitation of the sea from the Mesolithic to today (pp. 17-33). Oxford: Berghahn.

Cosgrove, D.E. (1984). Social formation and symbolic landscape. London, Sydney: Croom Helm.

Davoudi, S., \& Strange I. (2009). Space and place in the twentieth century planning: An analytical framework and an historical review. In S., Davoudi \& I., Strange (Eds.). Conceptions of Space and Place 
in Strategic Spatial Planning (Chapter 1, pp. 7-42). London: Routledge.

Döring, M., \& Ratter, B.M.W. (2015). 'Heimat' as a boundary object? Exploring the potentialities of a boundary object to instigate productive science-stakeholder interaction in North Frisia (Germany). Environmental Science \& Policy, 54, 448-455. https://doi.org/10.1016/j.envsci.2015.08.009

EC (2014). Directive 2014/89/EU of the European Parliament and of the Council of 23 July 2014 Establishing a Framework for Maritime Spatial Planning. Official Journal of the European Union, L 257/135.

Ehler, C., Zaucha, J., \& Gee, K. (2019). Maritime/Marine Spatial Planning at the Interface of Research and Practice. J., Zaucha \& K., Gee, (Eds.). Maritime Spatial Planning, Past, Present, Future (pp. 1-21). London, Cham: Palgrave Macmillan.

Ehler, C., \& Douvere, F. (2009). Marine Spatial Planning: a step-by-step approach toward ecosystem-based management. Intergovernmental Oceanographic Commission and Man and the Biosphere Programme, IOC Manual and Guides no. 53, ICaM Dossier no. 6, Paris: UNESCO.

Eisenhauer, B.W., Krannich, R.S., \& Blahna, D.J. (2000). Attachments to special places on public lands: an analysis of activities, reason for attachments, and community connections. Society and Natural Resources, 13(5), 421-441. https://doi.org/10.1080/089419200403848

Farmer, A., Mee, L., Langmead, O., Cooper, P., Kannen, A., Kershaw, P., \& Cherrier, V. (2012). The Ecosystem Approach in Marine Management. EU FP7 KNOWSEAS Project. ISBN 0-9529089-5-6.

Finke, G., Gee, K., Kreiner, A., Amunyela, M., \& Braby, R. (2020). The Introduction of Marine Spatial Planning in Namibia. Manuscript submitted for publication in Marine Policy.

Flannery, W., Healy, N., \& Luna, M. (2018). Exclusion and Non-participation in Marine Spatial Planning. Marine Policy, 88, 32-40. https://doi.org/10.1016/j.marpol.2017.11.001

Gee, K. (2010). Offshore wind power development as affected by seascape values on the German North Sea coast. Land Use Policy, 27, 185-194. https://doi.org/10.1016/j.landusepol.2009.05.003

Gee, K. (2015). Perceptions of the sea and seascapes: Challenges and opportunities. Presentation at the Coastal Places Workshop in Hamburg, Germany, 15th - 16th October 2015.

Gee, K., Kannen, A., Adlam, R., Brooks, C., Chapman, M., Cormier, R., Fischer, C., Fletcher, S., Gubbins, M., Shucksmith, R., \& Shellock, R. (2017). Identifying culturally significant areas for marine spatial planning. Ocean \& Coastal Management, 136, 139-147. https://doi.org/10.1016/j.ocecoaman.2016.11.026

Greverus, I.-M. (2006). Landschaftsreisen: Imagination - Erfahrung - Repräsentation. ZurÄsthetik der Landschaft. In B., Franzen \& S., Krebs (Eds.). Mikroland-schaften/Microlandscapes - Landscape culture on the move (pp. 101-136). Münster: Westfälisches Landesmuseum für Kunst und Kulturgeschichte.

Harvey, D. (1996). Justice, Nature and the Geography of Difference. Cambridge: Blackwell Publishers.

Hasse, J. (1999). Zum Verhältnis von Raum und Gefühl in der Anthropogeographie. Geographische Zeitschrift, 87(2), 61-62.

Haughton, G., \& Allmendinger, P. (2015). Fluid spatial imaginaries: Evolving estuarial city-regional spaces. International Journal of Urban and Regional Research, 39(5), 857-873. https://doi. org/10.1111/1468-2427.12211

Healey, P. (1998). Collaborative planning in a stakeholder society. Town Planning Review, 69(1), 1-21.

Healey, P. (2010). Making Better Places: the planning project in the twenty-first century. Basingstoke: Palgrave Macmillan.

Howard, P.M. (2019). Working grounds, producing places and becoming at home at sea. In T.J., King \& G., Robinson (Eds.). At home on the waves. Human habitation of the sea from the Mesolithic to today (pp. 34-61). Oxford: Berghahn.

Hull, R.B., \& Stewart, W.P. (1995). The landscape encountered and experienced while hiking. Environment and Behaviour, 27(3), 404-426. https://doi.org/10.1177/0013916595273007

Ingold, T. (2000). The perception of the environment: Essays in livelihood, dwelling and skill. London: Routledge.

Ingold, T. (2019). Afterword. In T.J. King \& G. Robinson (Eds.). At home on the waves. Human habitation of the sea from the Mesolithic to today (pp. 349-356). Oxford: Berghahn.

Ittelson, W.H., Franck, K.A., \& O'Hanlon, T.J. (1976). The nature of environmental experience. In S., Wap- 
ner, S.B., Cohen \& B., Kaplan (Eds.). Experiencing the environment (pp. 187-206). New York: Plenum. Janßen, H., Varjopuro, R., Luttmann, A., Morf, A., \& Nieminen, H. (2018). Imbalances in Interaction for Transboundary Marine Spatial Planning: Insights from the Baltic Sea Region. Ocean and Coastal Management, 161C, 201-210. https://doi.org/10.1016/j.ocecoaman.2018.05.008

Jay, S. (2010). Built at sea: marine management and the construction of marine spatial planning. Town Planning Review, 81(2), 173-191. https://doi.org/10.3828/tpr.2009.33

Jay, S. (2018). The shifting sea: from soft space to lively space. Journal of Environmental Policy \& Planning, 20(4), 450-467. https://doi.org/10.1080/1523908X.2018.1437716

Jessop, B., Brenner, N., \& Jones, M. (2008). Theorizing socio-spatial relations. Environment and Planning D: Society and Space, 26(3), 389-401. https://doi.org/10.1068/d9107

Jorgensen, B.S., \& Stedman, R. (2001). Sense of place as an attitude: lakeshore property owners' attitudes toward their properties. Journal of Environmental Psychology, 21, 233-248. https://doi. org/10.1006/jevp.2001.0226

Kaschuba, W. (1985). Alltagsweltanalyse in der regionalen Ethnographie: Kulturanthropologische Gemeindeforschung. In Analyse und Interpretation der Alltagswelt. Lebensweltforschung und ihre Bedeutung für die Geographie, Bamberger Protokolle 45. Köln: Thomas-Morus-Akademie Bensberg, Katholische Akademie in der Erzdiözese.

Kearns, R., \& Collins, D. (2012). Feeling for the Coast: The Place of Emotion in Resistance to Residential Development. Social \& Cultural Geography, 13(8), 937-955. https://doi.org/10.1080/146493 65.2012 .730150

Liquete, C., Piroddi, C., Drakou, E. G., Gurney, L., Katsanevakis, S., Charef, A., \& Egoh, B. (2013). Current Status and Future Prospects for the Assessment of Marine and Coastal Ecosystem Services: A Systematic Review. PLoS One, 8, pp. 15. https://doi.org/10.1371/journal.pone.0067737

Lowenthal, D. (1978). Finding valued landscapes. Progress in Human Geography, 2, 373-418. https:// doi.org/10.1177/030913257800200301

Mackinnon, I., Brennan, R. (2012). Belonging to the sea. Exploring the cultural roots of maritime conflict on Gaelic speaking islands in Scotland and Ireland. Scottish Crofting Federation and Scottish Association for Marine Science.

Merriam Webster (2019). Culture. Retrieved from https://www.merriam-webster.com/dictionary/ culture

McKinley E., Acott, T., \& Stojanovic, T. (2019). Socio-cultural Dimensions of Marine Spatial Planning. In J., Zaucha \& K., Gee (Eds.). Maritime Spatial Planning, Past, Present, Future (pp. 151-174). London, Cham: Palgrave Macmillan.

Morf, A., Cedergren, E., Gee, K., Kull, M., \& Eliasen, S. (2019). Lessons, stories and ideas on how to integrate Land-Sea Interactions into MSP. Stockholm: Nordregio.

Muir, R. (1999). Approaches to landscape. London: Macmillan Press.

Pyć, D. (2019). The Role of the Law of the Sea in Marine Spatial Planning. In J., Zaucha \& K., Gee (Eds.). Maritime Spatial Planning, Past, Present, Future (pp. 375-395). London, Cham: Palgrave Macmillan.

Ratter, B.M.W., \& Gee, K. (2012). Heimat: A German concept of regional perception and identity as a basis for coastal management in the Wadden Sea. Ocean \& Coastal Management, 68, 127137. https://doi.org/10.1016/j.ocecoaman.2012.04.013

Ratter, B.M.W. (2018). Geography of Small Islands: Outposts of Globalisation. Hamburg: Springer Nature. https://doi.org/10.1007/978-3-319-63869-0

Relph, E. (1976). Place and Placelessness. London: Pion.

Saar, M., \& Palang, H. (2009). The dimensions of place meanings. Living Reviews in Landscape Research, 3, 3. http://dx.doi.org/10.12942/Irlr-2009-3

Siedschlag, D. (2018). The concept of Emotional Vulnerability - a contribution to hazard research using the island of Pellworm as an example. Dissertation. Retrieved from https://ediss.sub.uni-hamburg.de/volltexte/2018/9227/

Steinberg, P. (2014). Foreword: On Thalassography. In J., Anderson \& K., Peters (Eds.). Water Worlds: Human Geographies of the Ocean (pp. xiii-xvii). Farnham: Ashgate. 
Tuan, Y-F. (1975). Place: An experiential perspective. Geographical Review, 65, 151-165.

Tuan, Y-F. (1977). Space and place: the perspective of experience. Minneapolis: University of Minnesota Press.

Tucholsky, K. (1929/2011). Deutschland, Deutschland über alles. Reinbek bei Hamburg: Rowohlt.

UNESCO (2019). Intangible Cultural Heritage. Retrieved from https://ich.unesco.org/en/what-is-intangible-heritage-00003

Urquhart, J., \& Acott, T. G. (2013). Re-connecting and Embedding Food in Place: Rural Development and Inshore Fisheries in Cornwall, UK. Journal of Rural Studies, 32, 357-364 https://doi. org/10.1016/j.jrurstud.2013.09.004

Wardenga, U. (2002). Räume der Geographie - zu Raumbegriffen im Geographieunterricht. Geographie heute, 23(200), 8-11.

Wickham-Jones, C. (2019). Seamless Archaeology. The evolving use of archaeology in the study of seascapes. In T.J., King \& G., Robinson (Eds.). At home on the waves. Human habitation of the sea from the Mesolithic to today (pp. 79-103). Oxford: Berghahn.

Williams, D.R., \& Stewart, S.I. (1998). Sense of place: an elusive concept that is finding a home in ecosystem management. Journal of Forestry, 5, 18-23. https://doi.org/10.1093/jof/96.5.18

Zaucha, J. (2019). Can Classical Location Theory Apply to Sea Space? In J., Zaucha \& K., Gee (Eds.). Maritime Spatial Planning, Past, Present, Future (pp. 97-119). London, Cham: Palgrave Macmillan. 
